\title{
Formation of periphyton biofilm and subsequent biofouling on different substrates in nutrient enriched brackishwater shrimp ponds
}

\begin{abstract}
Periphyton grown on substrates is known to improve water quality in aquaculture ponds. Five different substrates, (i) bamboo pipe (ii) plastic sheet (iii) polyvinylchloride (PVC) pipe (iv) fibrous scrubber, and, (v) ceramic tile were evaluated for the formation of biofilm in this experiment. The substrates were suspended $25 \mathrm{~cm}$ below the water surface. Each type of substrate was collected fortnightly to analyze the abundance and biomass of different periphytic algae and of the biofouling organism. The study was terminated after 60 days due to severe fouling by polychaete. Results showed that pond water nutrients were high on day 60 with mean total ammonia-N, nitrite-N and soluble reactive phosphorus concentrations of $309.6 \pm 8.6 \mu \mathrm{g} \mathrm{L}-1,26.0 \pm 2.7 \mu \mathrm{g} \mathrm{L}-1$ and $87.2 \pm 7.1 \mu \mathrm{g} \mathrm{L}-1$ respectively. During the first two weeks the substrates were colonized by 19 periphytic algae. The most abundant family was Bacillariophyta ( 8 genera) followed by Chlorophyta (7 genera) and Cyanophyta (4 genera). Periphyton colonization on bamboo pipe showed the highest $(\mathrm{p}<0.05)$ biomass in terms of chlorophyll a amongst all the substrates used. The biomass varied from 179 to 1137 $\mu \mathrm{g} \mathrm{m}-2$ with mean values of $1137.2 \pm 0.6,929.6 \pm 0.6,684.2 \pm 1.2,179.1 \pm 0.6$ and $657.0 \pm$ $0.6 \mu \mathrm{g} \mathrm{m}-2$ on bamboo pipe, PVC pipe, plastic sheet, fibrous scrubber and ceramic tile respectively for the first 15 days. From 3rd week, polychaetes began to form tubes on the substrate. By day 60 , the whole surface of all substrates was covered with tightly packed polychaete tubes with mean densities of $168.0 \pm 15.4,121.0 \pm 13.5,72.8 \pm 9.8,72.4 \pm 7.4$ and $56.0 \pm 6.8$ polychaete tubes $\mathrm{cm}^{-} 2$ for bamboo, PVC, plastic, fibrous scrubber and ceramic tile respectively. This study illustrated the invasive nature of attached polychaete thus hampering the formation of periphyton biofilm on substrates which could have been used for improving water quality in enriched brackishwater shrimp ponds.
\end{abstract}

Keyword: Biofouling, Substrates, Shrimp pond, Biofilm, Periphyton, Polychaete 